\title{
THE EFFECT OF SATURATED AND UNSATURATED FATTY ACID COMPOSITION IN BIO-BASED LUBRICANT TO THE TRIBOLOGICAL PERFORMANCES USING FOUR-BALL TRIBOTESTER
}

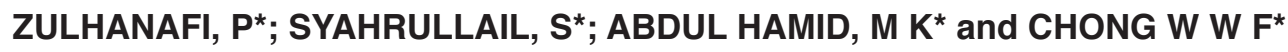

\begin{abstract}
The performances of bio-based lubricants were influenced by the strength of its molecular interaction between the fatty acid chain and iron molecules on metal surfaces. In this study, the fatty acid compositions of refined, bleached and deodourised palm oil (RBDPO), double fractionated palm olein (SPL) and palm mid olein (PMO) were determined by using gas-liquid chromatography (GLC). Four-ball tribotester was used to evaluate the performance of the lubricants in terms of friction coefficient, wear scar diameter (WSD) and surface roughness (Ra). It was found that PMO with high saturated fatty acid content exhibited excellent tribological characteristics subjected to various temperatures and rotational speeds. However, there was no significant impact observed at extreme pressure (EP) conditions. The physical wear condition was also discussed and analysed.
\end{abstract}

Keywords: bio-lubricant, saturated fatty acid, unsaturated fatty acid, tribology.

Received: 9 May 2020; Accepted: 29 January 2021; Published online: 16 March 2021.

\section{INTRODUCTION}

The global attention to green technology has driven researchers to channel their interest in environmental friendly resources. Mineral-based resources have been dominating technology development since the last century especially in most of the engineering applications including transportation, exploration, manufacturing industry, construction and many more. Mineralbased oil exhibited magnificent performance as it generally had long-life durability, high operating efficiency, less operating and maintenance cost and good adaptability to evolution. However, the main concern is the ability of the mineral oil to degrade to the environment naturally. Even

\footnotetext{
School of Mechanical Engineering,

Faculty of Engineering, Universiti Teknologi Malaysia,

81310 UTM Skudai, Johor, Malaysia.

E-mail: zulhanafipaiman@gmail.com
}

mineral-based oil offers excellent performances during the operation, but the waste oil has a high level of toxicity and non-biodegradable, thus, making it very difficult to be disposed off naturally (Syahrullail et al., 2013a; 2013b). There were some suggestions to turn the waste oil into other stable and eco-friendly compounds by chemical modification but it requires huge operating costs and not economically viable. As technology has to be continually developed, the remaining stock of mineral-based oil is also being questioned. In the third quarter of 2017 itself, people are consuming around 98 million barrels per day and predicted to keep increasing up to 110 million barrels per day in 2025 (Button, 2017). This should be the concern as it will take about a million years to recover the stock naturally. Synthetic-based oil might be one of the alternatives for further research. It possesses excellent viscosity properties, less evaporative loss, provides high torque and horsepower, able to extend the engine life, and possess good fluidity 
in both high and low temperature. However, in terms of production, it requires a higher cost when compared to mineral-based oil. Another plant-based vegetable oil resource which is highly degradable and possible to counter the environmental issues is the mineral oil-based lubricant.

\section{Palm Oil-based Lubricant}

Palm oil is currently dominating the food industry as cooking oil. Besides, it is also becoming more prominent in food dressing, pharmaceuticals, and toiletry products including detergents, soap bar production and many more. There is a lot of studies conducted to evaluate the performance of palm oil-based lubricants for engineering applications (Syahrullail et al., 2013c; Amiril et al., 2018; Noorawzi and Samion, 2016; Jabal et al., 2014; Razak et al., 2015; Hassan et al., 2016). Researchers are attracted to palm oil-based lubricants because of its properties. It has very stable thermo-viscosity properties indicated by the high viscosity index (VI). The viscosity of the oil does not vary much over temperature change. This would facilitate the operational control of the mechanism. Other than that, palm oil-based lubricants demonstrate high flash point, low volatility and good thermal stability. However, it also shows some instability when dealing with high-temperature applications because they are prone to oxidation. Some of the palm oil-based lubricants also have a high slip melting point and appeared as solid and semi-solid forms in ambient temperatures. This definitely would affect the fluidity of the lubricant. Several studies have been conducted to overcome these problems and found that some additives might be useful in showing significant improvement (Zulhanafi and Syahrullail, 2019).

The molecule structure of palm oil consists of hydrocarbon bonding between glycerol and fatty acid molecules. The combination of these molecular structures forms glycerides which creates several unique chains called di-glycerides and tri-glycerides for two and three fatty acid chain respectively. Normally, palm oil has a balanced saturated and unsaturated fatty acids in its molecular structure. Saturated fatty acid is usually dominated by palmitic acid C16 while unsaturated is presented by oleic acid C18:1. The unsaturated fatty acid chain is very unstable and actively reacts to other substrates especially oxygen which resulted in the formation of primary and secondary oxidation compound which affected the viscosity behaviour of the palm oil. Palm oil has a long polar fatty acid chain up to 24 chains and capable to provide strong intermolecular interaction with metal surfaces. The molecular bonding of fatty acid and steel structure is basically initiated by the fatty acid molecules itself. The formation of the thin monolayer is selfassembled when attached to metal surfaces. The strength of intermolecular bonding between fatty acid molecules and metal (oxide) surfaces were determined by the adsorption of saturated and unsaturated fatty acid molecules in both physical and chemical pathways. Lots of studies have been conducted to evaluate the factors that give impact to the fatty acid adsorption on the metal surfaces. This led to the characterisation of its frictional behaviour on metal contacts. Sahoo and Biswas (2009) investigated the frictional behaviours of saturated stearic acid and unsaturated linoleic acid on steel surfaces. They found that the unsaturated linoleic fatty acid yielded lower friction than saturated stearic acid. When a higher load is applied, the high charge double bond present on the backbone had encouraged the molecule's coupling with the steel substrate. Another effort was carried out by Crespo et al. (2018) in determining the impact of unsaturated fatty acid on the adsorption on the fatty acid layer. They discovered that the self-assembled thin monolayer fatty acid film formed weak interactions with the metal. The adsorption kinetics and coverage rate depend on the molecular architecture itself. Doig et al. (2014) investigated the performance of stearic and oleic acids as surfactants in squalane lubricant on ironoxide surfaces. They revealed that the double bond present in oleic acid molecules resulted in less penetration into surfactant film while stearic acid allows more lubricant penetration. However, as the surface coverage decreased, the friction coefficient is increased. The fatty acid adsorption on the metal surface is also influenced by the presence of moisture. Lundgren et al. (2011) studied the influence of moisture on the adsorption amount of unsaturated fatty acid. They found that 5.65\% mole of water increased the adsorption amount of linolenic acid but does not affect the friction and wear behaviours.

In this present study, the fatty acid composition of three types of palm oil was determined by using gas-liquid chromatography (GLC). This study was carried out based on the hypothesis that higher saturated fatty acid content (dominated by C16 and C18; palmitic and stearic acid) leads to having better tribological characteristics by providing stronger molecular interaction between alkyl chain and steel surfaces. The tribological performances of all three types of palm oil-based lubricants were evaluated in terms of friction coefficient, wear scar diameter (WSD), surface roughness (Ra) as well as physical wear characteristics. The tests were subjected to various temperatures, rotational speed, and extreme pressure (EP) conditions. The impact of saturated and unsaturated fatty acid content on tribological properties are analysed and discussed. 


\section{EXPERIMENTAL PROCEDURES}

The four-ball tribotester was used in this experiment as illustrated in Figure 1. This machine was developed to carry out the tribological tests for lubricant oil and greases at various temperatures, rotating speed and applied load. This machine consists of an oil test rig where the steel balls were placed and immersed in the lubricant oil. Thermocouple used to heat up and control the lubricant oil into the desired testing temperatures. The oil test rig was also attached to the friction torque sensors while the load is applied through the lever arm connected to the anti-friction disc. This machine was connected to the data logger in which all experimental data were recorded accordingly. Serious attention is needed during placing the test rig on the anti-friction disc to ensure the lubricant oil did not spill over.

\section{Apparatus}

The steel ball is made of chrome alloy steel with a $12.7 \mathrm{~mm}$ diameter following AISI E-52100 standard, extra polished (EP Grade 25), and hardened to 64-66 HRc (Rockwell C Hardness).

Three types of palm oil-based lubricants were tested in this study including refined, bleached and deodourised palm oil (RBDPO), double fractionated palm olein (SPL) and palm mid olein (PMO). All these oils were supplied by Keck Seng Sdn Bhd located in Pasir Gudang, Johor, Malaysia. The mineral-based lubricant oil Shell Omala (VG68) was used as benchmark in this study. The physical properties of all lubricant oils are tabulated in Table 1. (a)

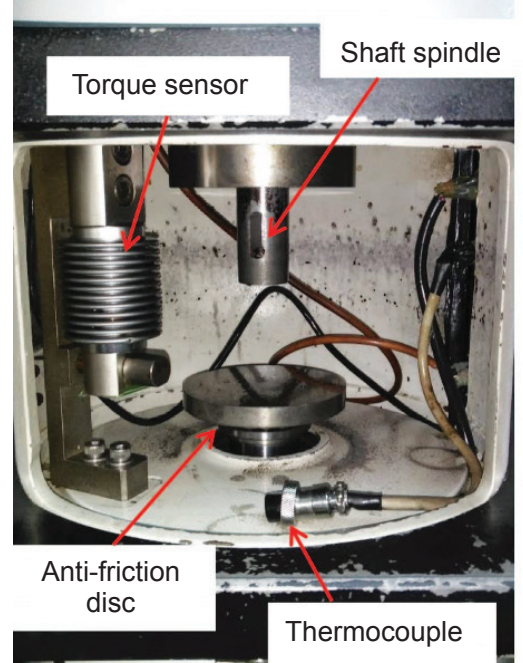

(b)

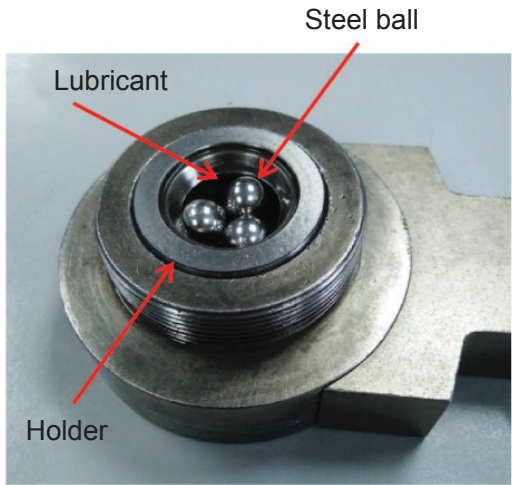

Figure 1. (a) Four-ball tribotester and (b) oil test rig.

TABLE 1. PHYSICAL PROPERTIES OF ALL TESTED LUBRICANTS

\begin{tabular}{lcccc}
\hline Properties & RBDPO & SPL & PMO & VG68 \\
\hline Density at $40^{\circ} \mathrm{C}\left(\mathrm{kg} \mathrm{m}^{-3}\right)$ & 0.8800 & 0.9000 & 0.8950 & 0.8870 \\
Kinematic viscosity $\left(\mathrm{mm}^{2} \mathrm{~s}^{-1}\right)$ & & & & \\
$\quad @ 40^{\circ} \mathrm{C}$ & 48.4 & 33.8 & 50.6 & 67.8 \\
$\quad 11.5$ & 12 & 13.2 & 8.7 \\
Viscosity index (VI) & 242 & 371 & 273 & 99 \\
Colour lovibond $(5.5$ inch cell R/Y) & $2.4 \mathrm{R} 24 \mathrm{Y}$ & $3.3 \mathrm{R} 33 \mathrm{Y}$ & $2.8 \mathrm{R} 28 \mathrm{Y}$ & - \\
Free fatty acid $(\mathrm{FFA} \%)$ & 0.05 & 0.08 & 0.10 & - \\
Peroxide value (PV) & 0.85 & 1.88 & 4.6 & - \\
Flash point $\left({ }^{\circ} \mathrm{C}\right)$ & 314 & 324 & 324 & 236 \\
Iodine value $(\mathrm{IV})$ & 52.5 & 65.57 & 48.23 & - \\
Slip melting point $\left({ }^{\circ} \mathrm{C}\right)$ & 33.8 & 15.8 & 24.5 & - \\
Cloud point $\left({ }^{\circ} \mathrm{C}\right)$ & $\mathrm{n} / \mathrm{a}$ & 4.5 & 18.5 & - \\
\hline
\end{tabular}

Note: RBDPO - refined, bleached and deodourised palm oil; SPL - double fractionated palm olein; PMO - palm mid olein; VG68 - mineral-based oil. 


\section{Methodology}

The inner section of the oil test rig was first checked and cleaned from any dirt and dust coming from the surrounding. The same goes for all four steel balls in which the pre-cleaning process was carried out by using industrial wipe before being flushed by dimethyl ketone (acetone). This step is crucial to ensure there were no unwanted particles that can ruin the friction measurement during the experiment. All three steel balls were then placed inside the oil test rig and left to self-arrange when the holder is tightened at approximately $68 \mathrm{Nm}$. The other steel ball was fixed inside the chuck and fitted into a shaft spindle which is driven by an electric motor. Then, approximately $10 \mathrm{ml}$ of lubricant oil was placed into the oil test rig. This amount was sufficient enough to ensure that all three steel balls are fully immersed and all contact surfaces are covered by the lubricant oil. The lubricant oil and steel ball can each only be used once. Each testing parameter will start with a new steel ball and fresh lubricant oil.

After completion, the oil test rig was placed on the anti-friction disc. This anti-friction disc is freely rotating and synchronised with the plunger movement. Then, the load was applied to the antifriction disc trough the plunger and the movement provided a relative load at a ratio of $1: 15$. The thermocouple was then fitted to the oil test rig to control the desired temperature. The experiment duration was set at the electrical panel before starting the experiment. The real-time reading for temperature, loads and friction torque was recorded on the computer accordingly.

\section{Experimental Condition}

The experimental condition for this study is tabulated in Table 2. The coefficient of friction value was computed using the following Equation.

$$
\text { Coefficient of friction, } \mu=\frac{T \sqrt{6}}{3 \mathrm{Wr}}
$$

where $\mathrm{T}$ is the friction torque in $\mathrm{kg} \mathrm{mm}^{-1}$. W presents the load applied in $\mathrm{kg}$, and $\mathrm{r}$ is the length between the centres of the contact surface on the lower balls to the rotation axis $(3.67 \mathrm{~mm})$.

\section{RESULTS AND DISCUSSION}

\section{Analysis on the Fatty Acid Composition using GLC}

The fatty acid composition of all palm oil-based lubricants was determined by using GLC. GLC analysis provided results of high precision and accuracy. Results with high sensitivity used less amount of sample, short analysis time, and capable to run both qualitative and quantitative analysis. In principle, GLC analysis is carried out by passing the sample (in a gaseous state) through the stationary liquid or solid phase and gaseous mobile phase. The sample was extracted into their individual component based on their affinity to the liquid and mobile phases. In another explanation, the sample is fractionated into their individual component between the mobile gas and stationary liquid phases. Generally, the inert gas such as nitrogen or helium was used as the carrier gas while non-volatile liquid comprises the stationary phase. For the mobile phase (carrier gas), the inlet column pressure was set to about 10-50 psi (above atmospheric pressure) with a controlled flow rate of about $25-50 \mathrm{ml} \mathrm{min} \mathrm{m}^{-1}$. The sample is injected into the flowing stream of the hot mobile phase by using a syringe. The mobile phase temperature is controlled at $50^{\circ} \mathrm{C}$ above the sample's boiling point to ensure vaporisation. The sample is then passed through the detectors whereby the electrical signal is generated based on the solute concentrations or mass flow rate. The separation of individual components is based on the differential migration between the mobile and stationary phases. The result is presented in a series of peaks whereby each peak represent the individual component passing through the detector. The retention time was used to identify the identity of the component while the total area under the peak represented the amount of component passing through the detector which is automatically calculated by the computer.

The fatty acid composition of all tested lubricants was tabulated as shown in Table 3. Saturated fatty acids were represented by lauric acid, myristic acid,

TABLE 2. EXPERIMENTAL CONDITIONS

\begin{tabular}{lll}
\hline \multicolumn{1}{c}{ Variable parameters } & \multicolumn{1}{c}{ Fixed parameters } & \multicolumn{1}{c}{ Standard } \\
\hline $\begin{array}{l}\text { Temperature varies from } 55^{\circ} \mathrm{C}, 65^{\circ} \mathrm{C}, 75^{\circ} \mathrm{C}, 85^{\circ} \mathrm{C} \\
\text { and } 95^{\circ} \mathrm{C}\end{array}$ & $\begin{array}{l}\text { Rotating speed at } 1200 \mathrm{rpm} \text { and fixed load of } \\
392 \mathrm{~N}\end{array}$ & ASTM D4172 B \\
$\begin{array}{l}\text { Rotating speed varies from } 1200 \mathrm{rpm}, 1600 \\
\text { rpm, } 2000 \mathrm{rpm} \text { and } 2400 \mathrm{rpm}\end{array}$ & $\begin{array}{l}\text { Temperature controlled at } 75^{\circ} \mathrm{C} \text { and fixed load } \\
\text { of } 392 \mathrm{~N}\end{array}$ & ASTM D4172 B \\
$\begin{array}{ll}\text { Extreme pressure }(\mathrm{EP}) \text { test starting at load of } \\
\text { 589 N. Additional } 198 \mathrm{~N} \text { was added until meet } \\
\text { the failure point }\end{array}$ & $\begin{array}{l}\text { Rotating speed controlled at } 1760 \pm 40 \mathrm{rpm} \text { and } \\
\text { temperature maintained at } 75^{\circ} \mathrm{C} \text {. Duration at } \\
\text { about } 10 \mathrm{sec}\end{array}$ & $\begin{array}{l}\text { ASTM D2783 (ASTM } \\
\text { International, 2019) }\end{array}$ \\
\hline
\end{tabular}


TABLE 3. FATTY ACID COMPOSITION

\begin{tabular}{lccc}
\hline Fatty acid composition (\%) & RBDPO & SPL & PMO \\
\hline Lauric acid C12 & 0.3 & 0.3 & 0.5 \\
Myristic acid C14 & 1.3 & 1.0 & 1.1 \\
Palmitic acid C16 & 43.5 & 34.3 & 45.0 \\
Stearic acid C18 & 4.7 & 3.6 & 6.4 \\
Oleic acid C18:1 & 39.4 & 47.5 & 37.3 \\
Linoleic acid C18:2 & 10.3 & 12.5 & 8.8 \\
Linolenic acid C18:3 & 0.3 & 0.4 & 0.2 \\
Arachidic acid C20 & 0.2 & 0.2 & 0.7 \\
\hline Total saturated fatty acid & $\mathbf{4 9 . 8}$ & $\mathbf{3 9 . 4}$ & $\mathbf{5 3 . 7}$ \\
Total unsaturated fatty acid & $\mathbf{5 0 . 2}$ & $\mathbf{6 0 . 6}$ & $\mathbf{4 6 . 3}$ \\
\hline
\end{tabular}

Note: RBDPO - refined, bleached and deodourised palm oil; SPL double fractionated palm olein; PMO - palm mid olein.

palmitic acid, stearic acid and arachidic acid while unsaturated fatty acids were represented by oleic acid, linoleic acid, and linolenic acid respectively. Generally, the crude palm oil has a balanced saturated and unsaturated fatty acid content, and the amount was literally changed by means of refining and fractionation process. SPL was produced through a double fractionation process whereby the palmitic acid was nucleated, crystallised and separated through filtration process, thereby improving its fluidity. A higher degree of fractionation process resulted in lower saturated fatty acid content in liquid (olein) fraction. Unlike PMO, even it was produced through a third degree fractionation process; it exhibited the highest saturated fatty acid content because it was derived from the solid (stearin) fraction which is palm mid fraction (PMF). Meanwhile, RBDPO was produced from the direct single refining process. It can be simplified that PMO as having higher saturated fatty acid content, followed by RBDPO and SPL respectively.

\section{Viscosity Behaviour Corresponding to Fatty Acid Content}

Figure 2 shows the viscosity behaviour of all tested lubricants over the increasing temperature. It was found that RBDPO showed identical viscosity trend with PMO, while SPL demonstrated better viscosity properties with respect to temperature rise. Meanwhile, VG68 showed higher viscosity at temperature of $40^{\circ} \mathrm{C}$ compared to RBDPO, $\mathrm{PMO}$ and SPL, however it exhibited no significant different at temperature of $50^{\circ} \mathrm{C}$ onwards. RBDPO experienced slightly high variance of its viscosity behaviour over the temperature rise, therefore leading to lower VI compared to SPL and PMO. It was attributed to the crystal structure on its molecules which can only be reduced by fractionation process. A higher degree of fractionation process leads to fewer crystal structures and reduce the slip melting point temperature. PMO was showing slightly lower VI compared to SPL. Both PMO and SPL are produced by a third-degree fractionation process. The higher VI indicated that the oil was more stable and the properties was not affected so much with temperature variations. Higher VI was advantageous especially during the boundary lubrication regime, in which the starting operating temperature was very low. The thermo-viscosity performance also affected the fluidity properties of the lubricants. SPL possessed

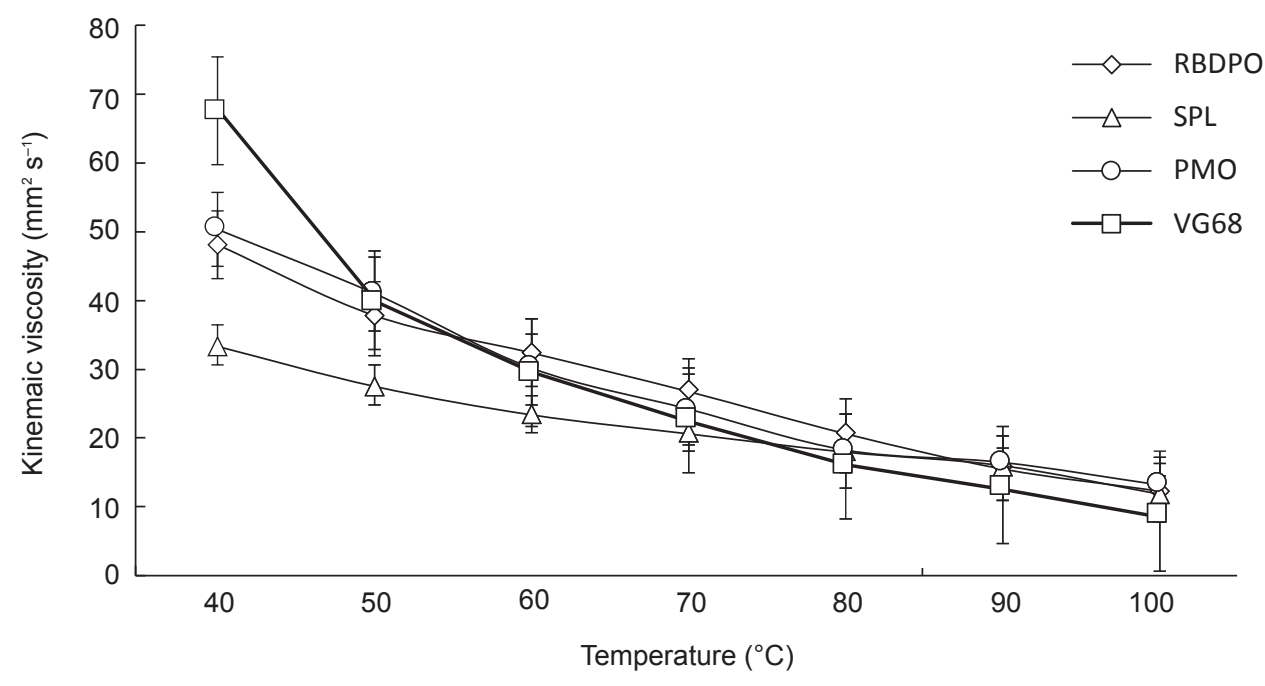

Note: RBDPO - refined, bleached and deodourised palm oil; SPL - double fractionated palm olein; PMO - palm mid olein; VG68 - mineralbased oil. 
better fluidity as it had the highest VI. The fluidity characteristics allowed the fatty acid molecules to freely move and facilitate the adsorption into the contacted surface. The very high viscosity readings showed that a huge amount of force was required to move the molecules to surround the ball (Habibullah et al., 2014). A very low viscosity lubricant was not recommended to be used as it will be easily cleared off with even a slight force, hence providing less surface protection. This would increase the coefficient of friction which is opposing the function of a lubricant.

In this case study, the correlation between fatty acid composition and viscosity behaviour was not significant. SPL with the highest unsaturated fatty acid content shows the highest VI. Meanwhile, the trend was found contradictory for both RBDPO and PMO. PMO with less unsaturated fatty acid content, has shown higher VI than RBDPO. Even RBDPO, with the most balanced saturated and unsaturated fatty acid content, could not guarantee a better thermal-viscosity behaviour.

\section{Analysis on Friction Behaviour at Different Temperature}

The coefficient of friction trend at various temperatures was plotted as presented in Figure 3. Generally, there were no such common behaviours shown by all tested lubricants. On average, PMO had demonstrated the lowest coefficient of friction among the palm oil-based lubricants tested. In comparison to the mineral-based oil, VG68 exhibited the lowest coefficient of friction at low temperature of $55^{\circ} \mathrm{C}$ and was slightly higher compared to RBDPO and $\mathrm{PMO}$ at $65^{\circ} \mathrm{C}$ onwards. At low temperatures,
RBDPO exhibited a higher coefficient of friction; attributed to its viscosity behaviour. RBDPO showed high viscosity that was affected by its fluidity. The fatty acid molecule was hardly moving around and therefore form an improper close-packed monolayer soap film, which resulted in a high coefficient of friction. On the other hand, low viscosity oil had allowed fatty acid molecules to provide stickiness and affinity on the metal surfaces which reduced its movement on peripheral areas to reduce friction (Sapawe et al., 2016). As the temperature increased, RBDPO and PMO showed a decreasing trend and only slightly increased towards the end of the experiment. Meanwhile, SPL showed increasing trend of coefficient of friction with increasing temperature. SPL has higher unsaturated fatty acid content compared to other lubricants. An unsaturated fatty acid chain possessed a double bond that is unstable and actively reacting to other substrates. At a temperature of $75^{\circ} \mathrm{C}$, the presence of oxygen had caused the oxidation process to take place. Higher unsaturated fatty acid content led to higher oxidation reaction. The oxidation process would cause the breakage of the thin soap film which is supposed to protect the mating surfaces. The main oxidation and subsequent reaction with other lipid molecules produced peroxyl radicals and hydroperoxides that affect the viscosity of the lubricant (Aluyor and Ori-Jesu, 2008). Even palm oil-based lubricants which have natural antioxidants like tocotrienols and carotenoids, was still unable to counter and protect the double bond from being attacked by oxygen molecules. High unsaturated fatty acid molecule content had led to a high oxidation reaction which resulted in a higher coefficient of friction.

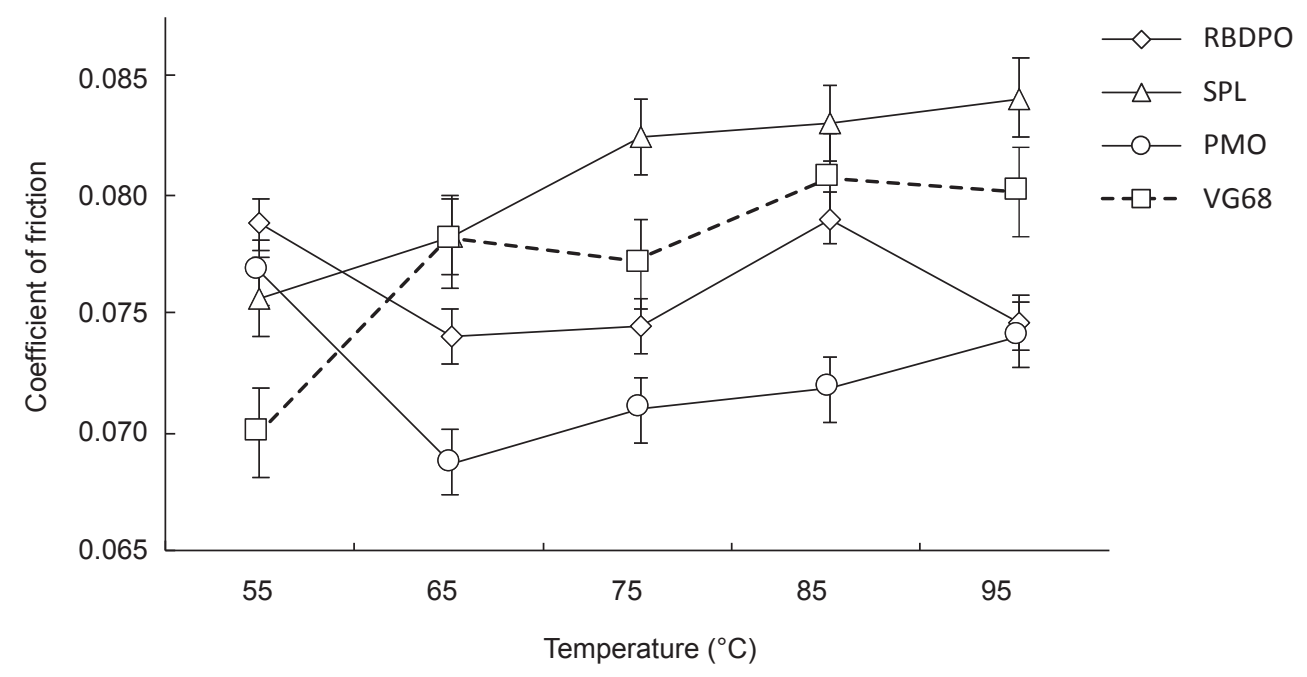

Note: RBDPO - refined, bleached and deodourised palm oil; SPL - double fractionated palm olein; PMO - palm mid olein; VG68 - mineralbased oil. 


\section{Analysis on Friction Behaviour at Different Speeds}

Figure 4 demonstrates the coefficient of friction behaviour against various rotational speeds. It was found that PMO consistently provided a lower coefficient of friction compared to RBDPO and SPL at all testing speeds. As the speed increased, PMO showed a drastic reduction in coefficient of friction and only slightly increased at the speed of $1600 \mathrm{rpm}$ and $2400 \mathrm{rpm}$. Apparently, RBDPO and SPL showed a decreasing trend of the coefficient of friction at increasing speed. It was also observed that VG68 showed higher coefficient of friction compared to all palm oil-based lubricants at all speeds tested. This is because the palm oil has a long polar fatty acid chain that provided surface protection by the formation of thin layer soap film. These long polar fatty acid chains in the molecule structures have a natural physical affinity that provides strong interaction with metal surfaces. This strong interaction has the capability to reduce the tangential forces carried by the asperities and support the entire load to maintain the existence of the thin layer soap film thus, minimising the surface contact. The increasing rotational speed definitely would lead to an increase in temperature by the heat generated, thus, resulting in a natural oxidation reaction. This was actively accelerated and disrupted the thin layer soap film formed by the fatty acid chain molecules. SPL which possessed higher unsaturated fatty acid content was highly exposed to the oxidation reaction. Meanwhile, PMO which has less unsaturated fatty acid content showed minimum effects of oxidation and maintained a low coefficient of friction at all speeds. The thin layer soap film was generally fixed to the metal surfaces through physisorption and chemisorption binding mechanism. During the formation of these thin layers of soap film, the unsaturated fatty acid was highly attracted to the metal surfaces through long-range interaction. When it touched the metal surfaces, the polar head will penetrate into the metal surface and the Van der Waals forces in the molecules will self-aligned, parallel to each other to form the close-packed monolayer. The first thin layer soap film has stronger binding energy through a chemisorbed mechanism while the upcoming layer (physisorbed) formed by saturated fatty acid was less durable and easily be rubbed away with a sliding motion. A higher degree of unsaturated fatty acid indicated a higher amount of physisorbed layers, which are less protective to the metal surfaces as shown by SPL. The continuous sliding motion weakens the intermolecular bindings which eliminates the thin layer soap film thus, increased friction.

\section{Analysis on Friction Behaviour under Extreme Pressure (EP)}

Under EP conditions, the load was applied starting from $393 \mathrm{~N}$, adding $196 \mathrm{~N}$ until it reaches the failure point. The characteristic of the coefficient of friction towards EP condition was plotted as illustrated in Figure 5. It was observed that all tested lubricants were exhibiting low coefficient of friction at a load of $393 \mathrm{~N}$ and $589 \mathrm{~N}$ which is less than 0.10 . At a load of $786 \mathrm{~N}$, there was a small increment shown by all tested lubricants with RBDPO, which exhibited higher friction while SPL demonstrated the lowest. As the load increased to $981 \mathrm{~N}$, SPL showed a drastic increment while RBDPO and PMO maintained an increasing trend. There were

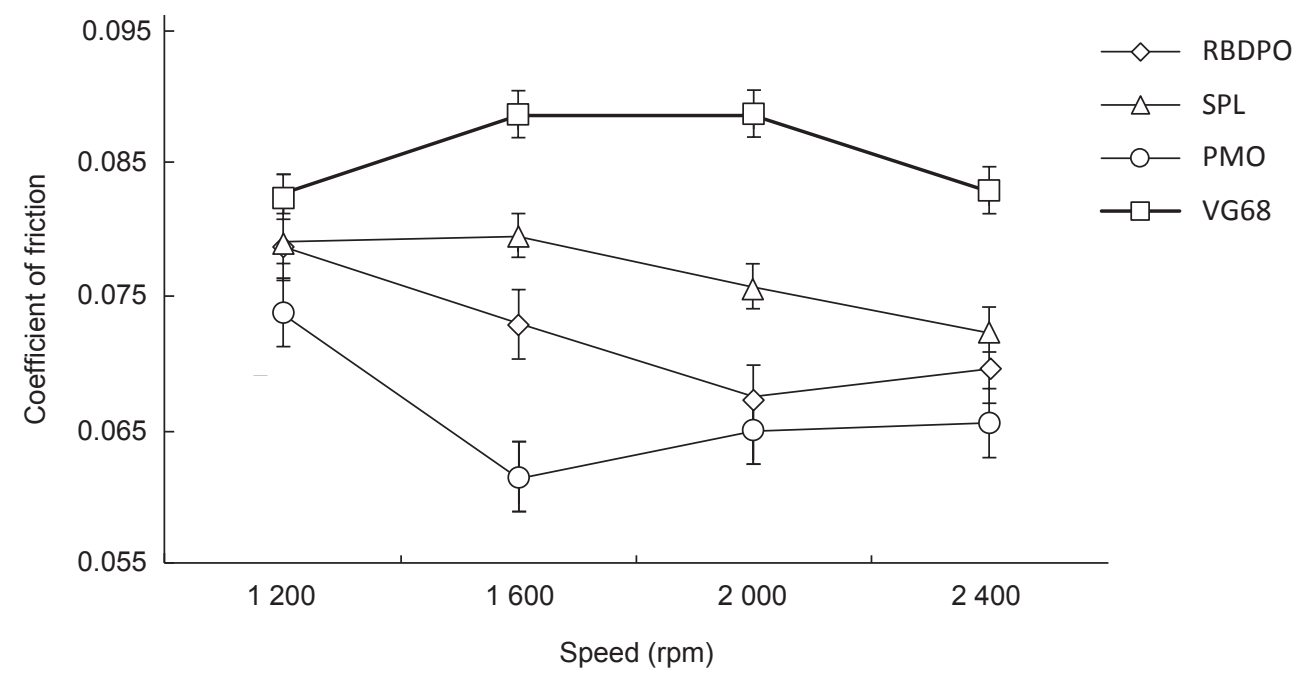

Note: RBDPO - refined, bleached and deodourised palm oil; SPL - double fractionated palm olein; PMO - palm mid olein; VG68 - mineralbased oil. 


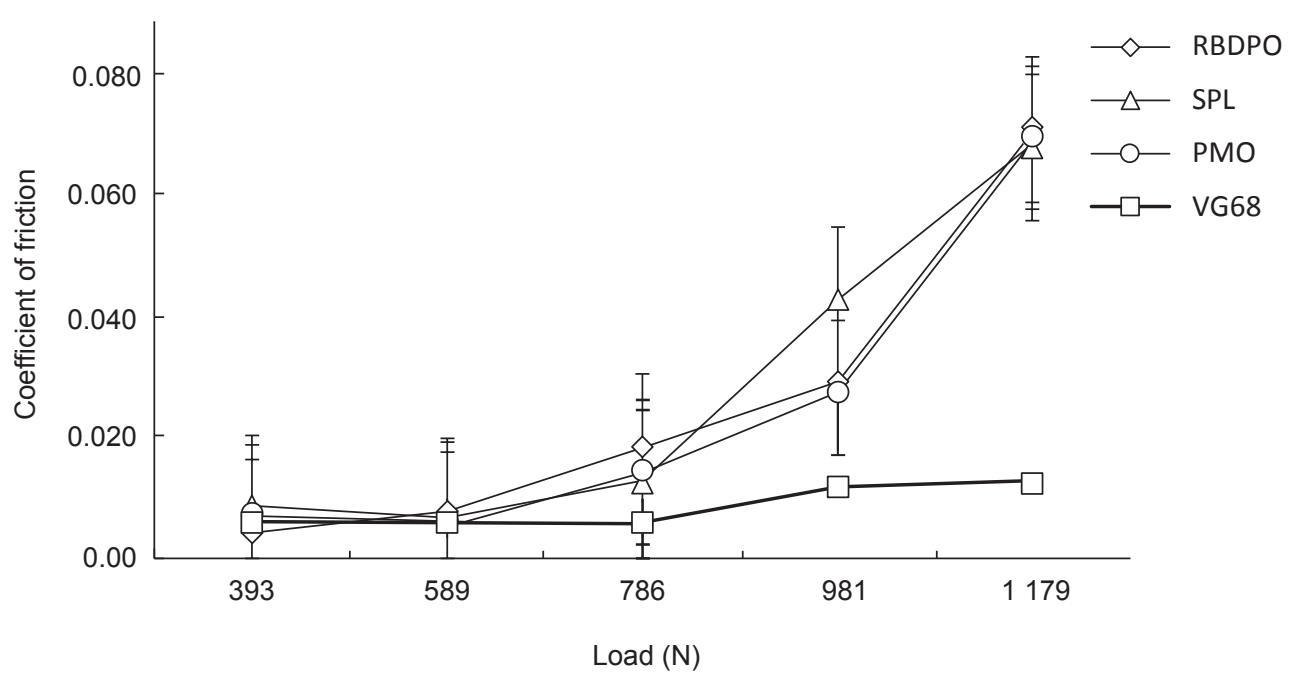

Note: RBDPO - refined, bleached and deodourised palm oil; SPL - double fractionated palm olein; PMO - palm mid olein; VG68 - mineralbased oil.

Figure 5. Coefficient of friction under extreme pressure condition.

no significant differences at load of $1179 \mathrm{~N}$ in which all tested lubricants showed a high coefficient of friction. It was also observed that the steel ball was found welded and considered meeting the failure point at a load of $1179 \mathrm{~N}$. Apparently, it was found that VG68 maintained the low coefficient of friction even at a maximum testing load of $1179 \mathrm{~N}$. Owing to its oil formulation, it did not deteriorate even when operating at harsh condition. The capability of the fatty acid chain to support the load is determined by the closely packed alkyl chain that reacts with a cumulative short range of Van der Waals forces between neighbouring methyl groups (Crespo et al., 2018). Higher closely packed density provided better affinity on the metal surface. The unsaturated fatty acid has a double bond on its ninth and tenth carbon chain. This double bond caused the oleic acid (unsaturated) to form a cis-configuration which bends the molecules and hence difficult to form a linear molecule configuration. Therefore, the unsaturated fatty acid is favourably less effective in forming a closely-packed monolayer soap film. A less closely packed density would lead to less affinity of the fatty acid chain molecules to the metal surfaces. Unlike the saturated fatty acid which is consisted of palmitic and stearic acids, the trans-isomer configuration of the molecules is able to pack efficiently on the metal surfaces. PMO with high saturated fatty acid content therefore demonstrated good molecule packing ability thus, protecting the metal surface with lower coefficient of friction. However, at such a higher load of 1179 $\mathrm{N}, \mathrm{PMO}$, with higher saturated fatty acid was still unable to protect the contact surfaces. Natural oxidation and continuous sliding motion have therefore broke the thin layer soap film which caused the failure.

\section{Analysis on the WSD at Various Temperatures}

The WSD was measured by using a highresolution microscope equipped with I-Lite software. All three steel balls were measured and the average WSD was plotted as shown in Figure 6. It was observed that the increase in temperature had increased the WSD for all tested lubricants. VG68 exhibited lower WSD compared to others lubricant, which previously showed higher coefficient of friction. It is because VG68 was well formulated with antiwear additive which does not cause oxidation reaction. At a low temperature of $55^{\circ} \mathrm{C}$, SPL demonstrated a lower WSD compared to PMO and RBDPO. Even SPL was having a higher content of unsaturated fatty acids; hence it does not affect the development of wear scar. However, starting at a temperature of $65^{\circ} \mathrm{C}$, SPL had shown a significant drastic increment of WSD compared to other lubricants. Apparently, the trend kept increasing as the temperature increased to $95^{\circ} \mathrm{C}$. The increase in WSD was mainly attributed to the breakage of thin layer soap film through an oxidation process. Similar to the analysis of friction at various temperatures, the increase in temperature had caused the oxygen molecules to become more aggressive and actively react to the double bonds available in the unsaturated fatty acids, which include oleic acid, linoleic acid and linolenic acid. The oxidation reaction also caused the formation of primary and secondary oxidation products including acetic acid, formic acid, propionic acid and caproic acid (Haseeb et al., 2010). The formation of these acids created an active reaction with iron molecules on the metal surfaces and caused the metal surfaces to become more brittle which later crumbled, therefore enlarging the wear scar formation (Mannekote and Kailas, 


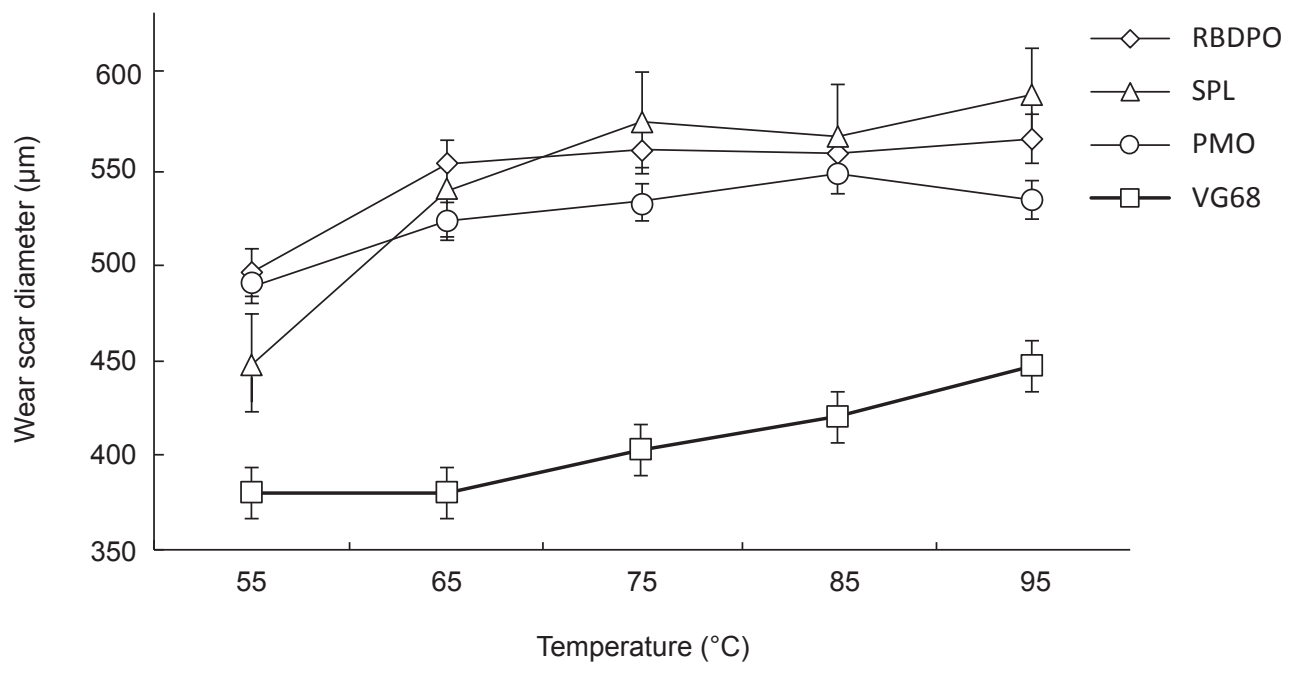

Note: RBDPO - refined, bleached and deodourised palm oil; SPL - double fractionated palm olein; PMO - palm mid olein; VG68 - mineralbased oil.

Figure 6. Wear scar diameter at various temperatures and speed of $1200 \mathrm{rpm}$.

2012). The primary and secondary products which were produced during the oxidation process will also contaminate with the lubricant oil and increase the viscosity. The increase in viscosity leads to an increase in friction and simultaneously increases the WSD. PMO, with less unsaturated fatty acid content, should promote consistent WSD development due to less impact on the oxidation process.

\section{Analysis on the WSD at Different Speeds}

The WSD behaviour at various rotational speeds was plotted as shown in Figure 7. In general, the results revealed that the WSD is increased proportionally with the increase in rotational speed for all tested lubricants. Apparently, the results contradicted with the coefficient of friction analysis at different speeds. It was observed that the coefficient of friction had decreased while WSD had increased with increasing speed. A similar phenomenon was found by Fazal et al. (2013) in characterising the wear and friction behaviour of bio-based lubricants. Similarly, to WSD trend in various temperatures analysis, VG68 exhibited lower WSD compared to others lubricant. It was also observed that SPL which experienced a higher coefficient of friction at all tested speed exhibited higher WSD compared to other lubricants. SPL with a higher content of unsaturated fatty acid, had formed less packed molecules of the thin layer

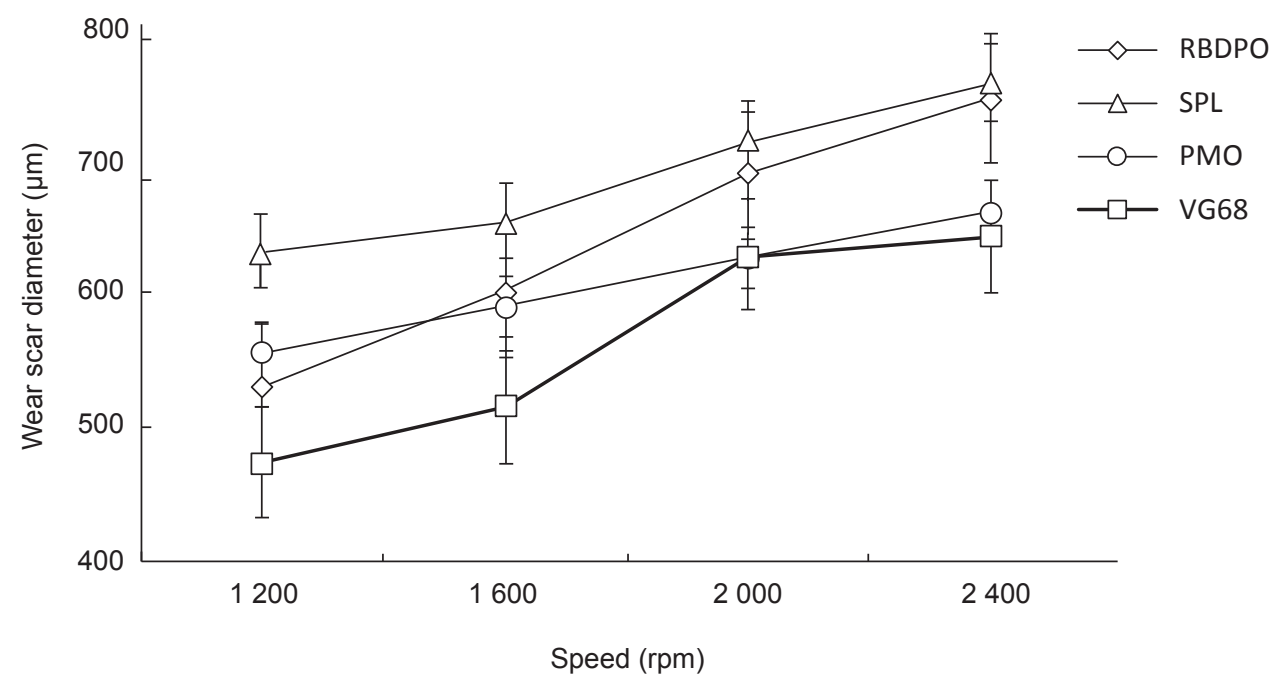

Note: RBDPO - refined, bleached and deodourised palm oil; SPL - double fractionated palm olein; PMO - palm mid olein; VG68 - mineralbased oil. 
soap film on the metal surfaces. The less packed molecules formed by unsaturated fatty acid was mainly due to the increase of entanglement between the molecules in opposing layers (Lundgren et al., 2008). Unsaturated fatty acid, mainly dominated by oleic acid, also has 'shorter' and 'thinner' molecules compared to saturated acid (stearic acid) due to the presence of $\mathrm{C} 9=\mathrm{C} 10$ cis double bond. The response of oleic acid to the molecular elongation under shear stress was less sensitive to surface coverage. It was because oleic acid has intrinsic molecular rigidity, which will lead to less efficient packing density and contributed to less affinity to the metal surfaces. Unlike PMO which has a higher content of stearic acid, the magnitude of elongation molecules was mainly attributed to the crowding effects of neighbouring absorbed molecules (Doig et al., 2014). In addition, stearic acid which has 'slimmer' molecules; no branching and no cyclic components, had exhibited more packed and closed monolayer soap film molecules. This kind of monolayer provided a stronger soap film with higher lateral cohesive forces between fatty acid molecules and metal surfaces. RBDPO showed slightly lower WSD compared to PMO at speed of $1200 \mathrm{rpm}$. However, at higher speeds of $2000 \mathrm{rpm}$ and $2400 \mathrm{rpm}, \mathrm{RBDPO}$ exhibited 3\% lower WSD compared to SPL. Basically, RBDPO has quite a balanced saturated and unsaturated fatty acids, which also experienced oxidation reaction but the impact was always in between PMO and SPL. It can be seen clearly that PMO with higher saturated fatty acid content had promoted fewer impacts of high sliding motion to the metal surfaces which led to lower WSD formation compared to other lubricants.

\section{Analysis on the WSD under EP}

Figure 8 presented the WSD behaviour under $\mathrm{EP}$ conditions. There were no significant differences observed at a load of $393 \mathrm{~N}$ and $589 \mathrm{~N}$ for all tested lubricants. WSD was consistent even when an additional $198 \mathrm{~N}$ load has been added. At a load of 786 N, PMO and RBDPO exhibited a slightly higher increment of WSD compared to SPL. At a higher load of $981 \mathrm{~N}$, PMO showed less WSD increment while RBDPO and SPL exhibited higher increments respectively. At a maximum load of $1179 \mathrm{~N}$, it was found that the steel balls lubricated by all tested lubricants were found to be welded and considered reaching the failure point. The experiment was stopped at this point and no additional load was added as the WSD recorded had exceeded 4 $\mathrm{mm}$. According to ASTMD2783 standards, the experiment was considered meeting its failure point if WSD recorded had exceeded $4 \mathrm{~mm}$ (Totten et al., 2003). Apparently, VG68 was able to maintain WSD less than $4 \mathrm{~mm}$ at maximum testing load of $1179 \mathrm{~N}$. The failure point of VG68 was not defined in this study. The wear scar formation was mainly linked to the failure of lubricant to protect the metal surface from harsh contact. The thin monolayer soap film is responsible to counter the tangential pressure given by the load thus, minimise the asperities contact and hence reduced WSD. At EP condition, the continuous sliding motion with such high load definitely will generate heat which accelerated the oxidation reaction. The increase in WSD indicated that the thin monolayer soap film had totally broken down and no longer protect the metal surfaces. The breakage of these soap films was mainly caused by the oxidation process due to the loosely-packed

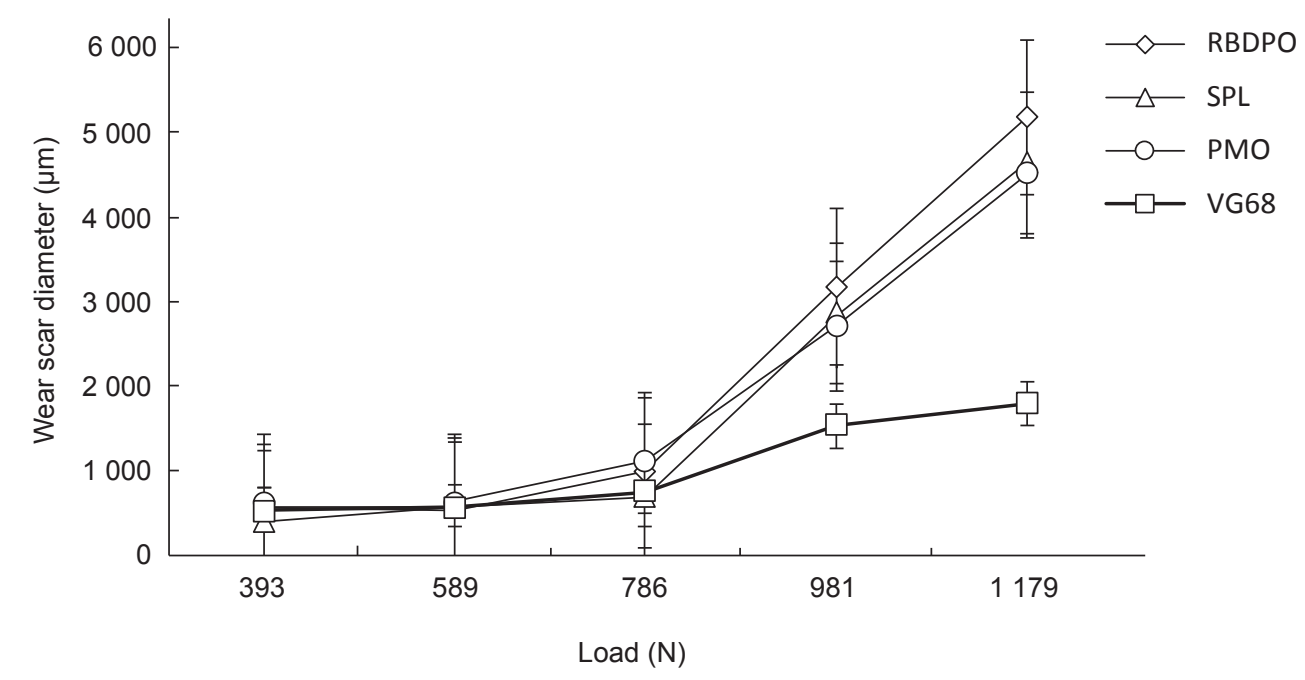

Note: RBDPO - refined, bleached and deodourised palm oil; SPL - double fractionated palm olein; PMO - palm mid olein; VG68 - mineralbased oil. 
molecules of the unsaturated fatty acid. Sharma et al. (2009) suggested that at such a higher load, the thin layer soap film had slipped away from the metal surface while absorbing the ester ends of the fatty acid chain. In another explanation, the formation of thin monolayer soap film on the metal surface had contributed to good friction reduction, however, the intermediate coverage of unsaturated fatty acid might have increased the wear formation. This is due to the reduced wettability of the bulk oil on the metal surface. Therefore, the unsaturated fatty acid had exhibited a detrimental effect on the contact surfaces (Kondo, 1997). In this analysis, the impact of saturated and unsaturated fatty acid on WSD at EP condition was not significant. PMO with a higher content of saturated fatty acid was also unable to retain the formation of closelypacked monolayer soap film at EP condition thus, had increased the WSD.

\section{Analysis of Surface Roughness (Ra) under EP}

The Ra of the wear scar was measured and determined by using a surface profilometer equipped with Surftest software. The needle pin from the machine is located perpendicular on the wear scar surface which travel along the WSD. In this analysis, the average $\mathrm{Ra}$ at different extreme load pressure was plotted as illustrated in Figure 9. Higher Ra value indicated that the wear scar has coarser surfaces. Generally, the roughness of the metal surfaces is attributed to the asperities contact between two mating surfaces. The wear surfaces that have huge differences in peak and valley depth resulted in higher $\mathrm{Ra}$. It was found that there was no significant difference observed by all tested lubricants at a load of $589 \mathrm{~N}$ and $786 \mathrm{~N}$ respectively. The wear formed has a smooth surface even when there is slight increase in WSD at a load of 786 N. At a higher load of 981 N, SPL demonstrated a higher increment of Ra compared to RBDPO and PMO. Meanwhile, VG68 exhibited smoother surface compared to other lubricants at higher loads of $981 \mathrm{~N}$ and $1179 \mathrm{~N}$. As discussed in WSD analysis at different temperatures, the increase in load leads to an increase in temperature and definitely initiated the oxidation process. SPL which has a higher content of unsaturated fatty acid experienced a high impact of the oxidation process. The reaction between the oxidation products and iron molecules caused brittleness which weaken the metal surfaces (Farhanah and Syahrullail, 2016; Quinchia et al., 2014). This will allow more asperities contact which lead to a coarser surface. RBDPO and PMO with a higher content of saturated fatty acids, were able to form a more packed thin layer soap film and therefore minimised the asperities contact, thus, promoting a smoother surface. At a higher load of Ra compared to RBDPO and SPL. At this point, the $\mathrm{Ra}$ analysis will be based on the physical wear appearances.

\section{Physical Wear Appearances at Different Temperatures and Speeds}

The physical wear conditions at high temperatures are as shown in Figure 10. The images were taken by using a high resolution microscope with anti-reflection and equipped with I- Solution software. The analyses were done with regards to the major affected area of physical wear surfaces. At a temperature of $85^{\circ} \mathrm{C}$, there were a few darker lines

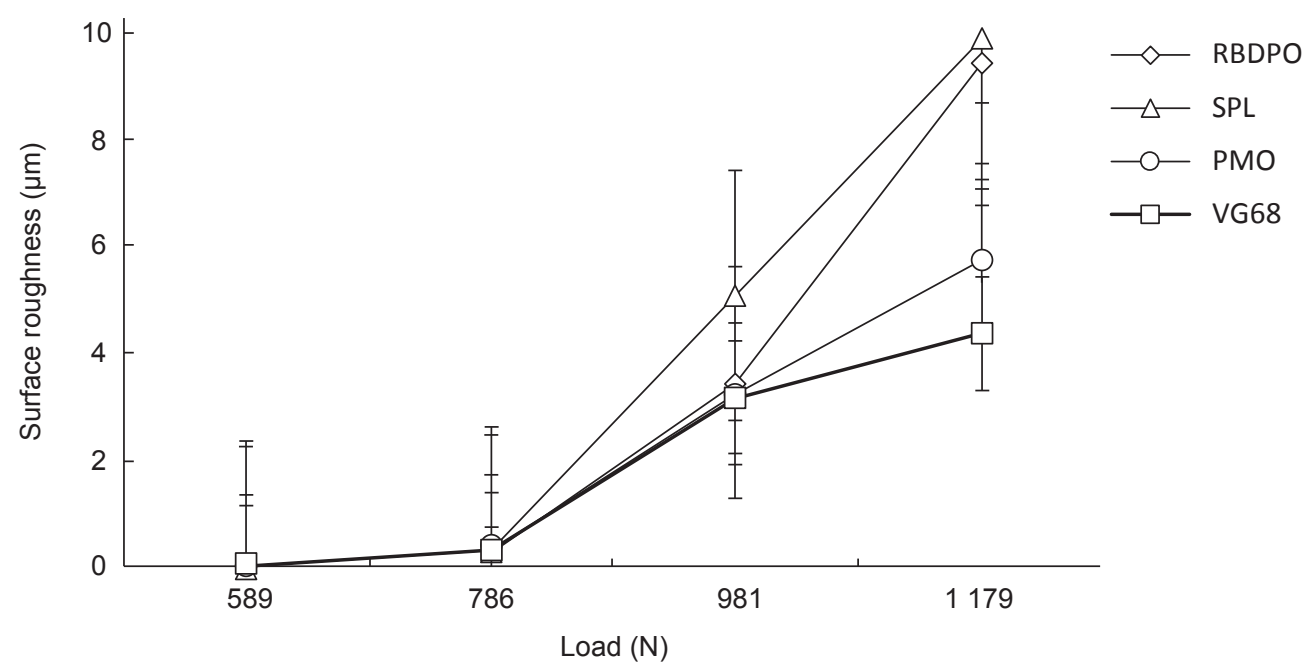

Note: RBDPO - refined, bleached and deodourised palm oil; SPL - double fractionated palm olein; PMO - palm mid olein; VG68 - mineralbased oil. 

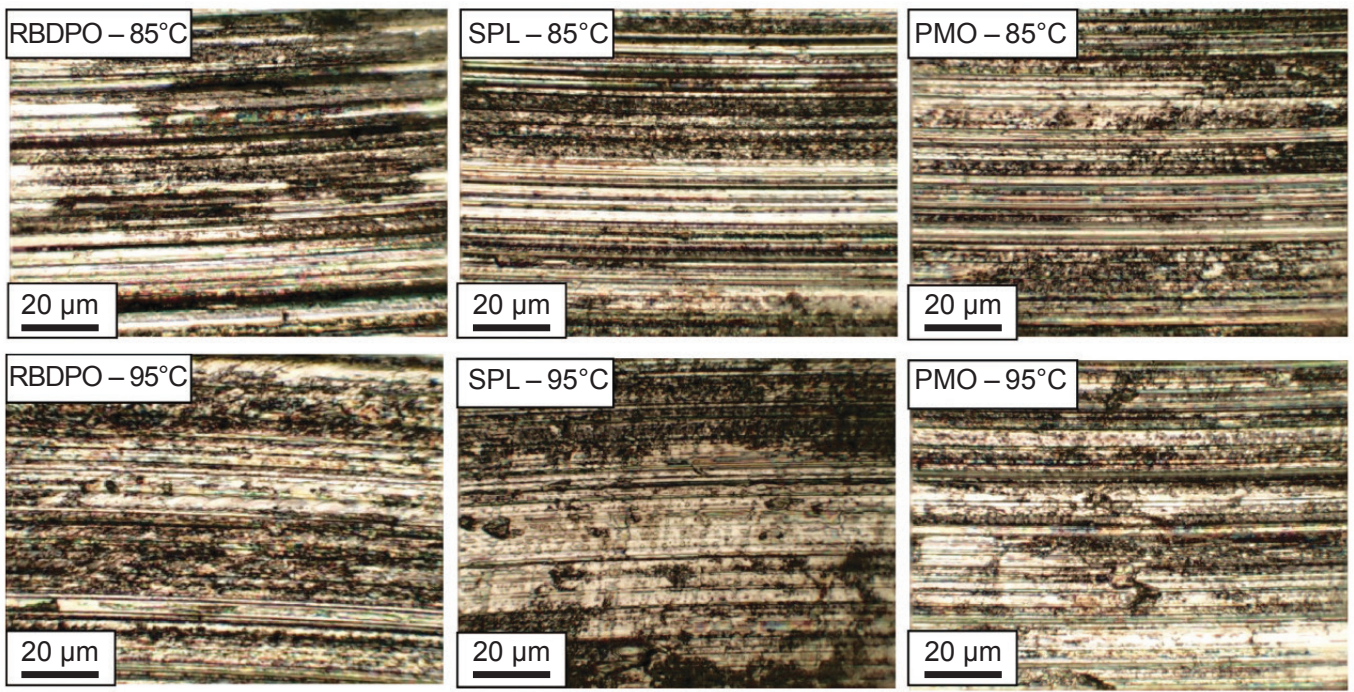

Note: RBDPO - refined, bleached and deodourised palm oil; SPL - double fractionated palm olein; PMO - palm mid olein.

Figure 10. Physical wear appearances at high temperatures and speed of $1200 \mathrm{rpm}$.

observed on the wear surface lubricated by RBDPO. Darker lines indicated deeper scratches, caused by heavy asperities contact. For SPL and PMO, only light scratches were observed with no major defect on the wear surfaces. At a higher temperature of $95^{\circ} \mathrm{C}$, the steel ball lubricated by SPL had exhibited a darker surface area compared to RBDPO and PMO. This was caused by the oxidation effect experienced by SPL which has a high content of unsaturated fatty acid. It was also observed that no major scratches were found on the surfaces. It can be suggested that there was no significant impact of saturated and unsaturated fatty acid content on the physical wear at high temperatures as on average, all lubricants had demonstrated similar appearances of wear surface. All dark light scratches were categorised as abrasive and no adhesive was spotted on the wear surfaces (Fazal et al., 2013).

Meanwhile, the physical wear appearances of surfaces at high rotational speed are as illustrated in Figure 11. It was observed that at a speed of $2000 \mathrm{rpm}$, RBDPO and PMO exhibited light and dark scratches on the wear surfaces. There was also no major defect which was considered as abrasive wear. Unlike SPL, there was one dark spot area and minor defect detected on its wear surface as highlighted in boxes. The upper box indicated that the area experienced localised heating and might be caused by the high rotational speed. The lower box indicated minor adhesive wear in which a small amount of the metal
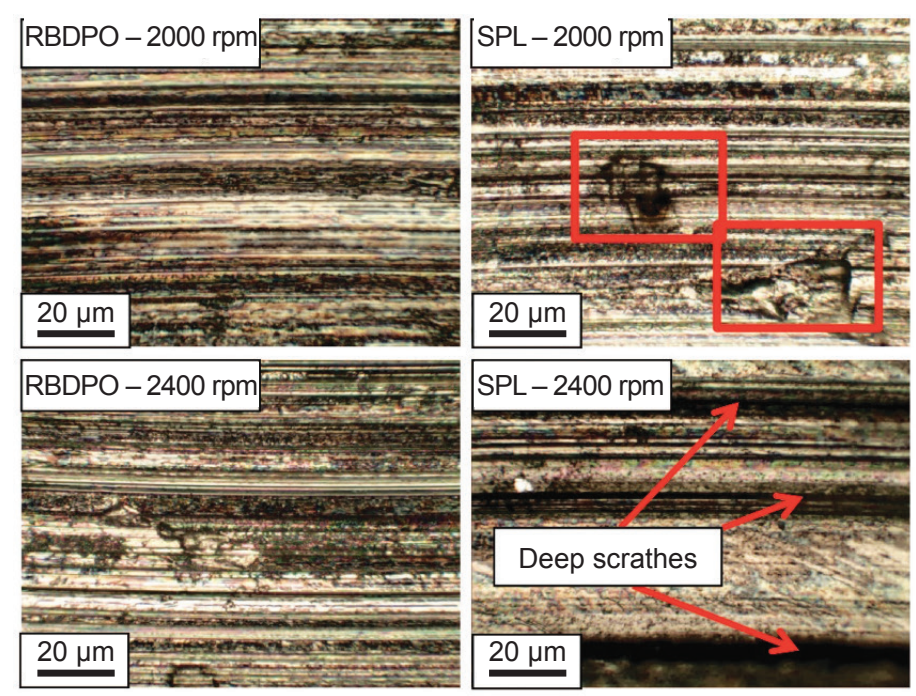

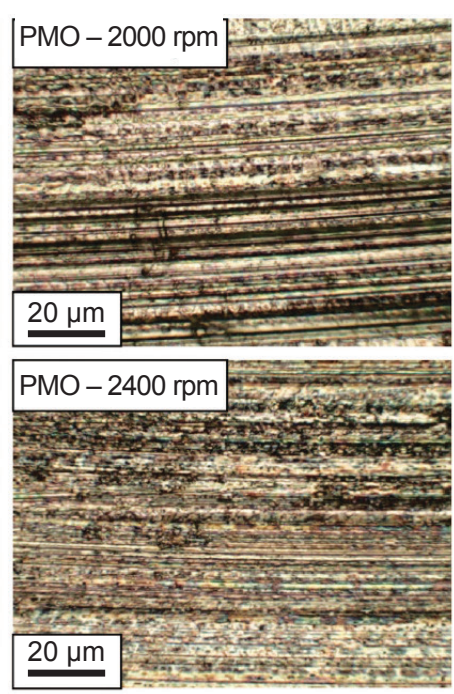

Note: RBDPO - refined, bleached and deodourised palm oil; SPL - double fractionated palm olein; PMO - palm mid olein.

Figure 11. Physical wear appearances at high speeds and temperatures of $75^{\circ} \mathrm{C}$. 
surface has slightly slipped out from its original position. At a higher speed of $2400 \mathrm{rpm}, \mathrm{RBDPO}$ and PMO demonstrated average wear scar condition of which a mild dark area was found on almost all the wear surfaces. There is no major defect or deep scratches found which was considered as abrasive wear. Apparently, SPL experienced a deep impact as three dark lines were spotted on the wear surfaces which indicated deep scratches. As explained in the previous analysis, SPL have a high content of unsaturated fatty acid, and high rotational speed had increased the temperature, thus, initiated the oxidation process (Zulkifli et al., 2013; Mobarak et al., 2014). The reaction between the oxidation products and iron metal has thus, weakened them and allow more asperities to go deeper into the metal surface.

\section{Physical Wear Characterisation under EP Condition}

Figure 12 presented the physical wear appearances under EP conditions. Figure 12a, $d$ and $e$ were taken by using a high resolution microscope while the rest were captured by using a lowresolution microscope. It was observed that at a load of $786 \mathrm{~N}$, RBDPO and SPL showed a round shaped wear scar while PMO demonstrated bigger WSD. There was a dark area spotted on the wear surfaces of both RBDPO and PMO as highlighted in Figure $12 a$ and $g$. This was attributed to the oxidation process whereby the oxygen molecules were attacking double bonds in unsaturated fatty acid chain molecules. Dark spots indicated that the area was badly affected by the oxidation reaction and polymerised (Sapawe et al., 2016). Meanwhile, SPL presented a fair wear scar formation with light abrasive wear and no adhesive wear observed. It was totally agreed with a previous analysis in which SPL showed the lowest coefficient of friction and the smallest WSD at $786 \mathrm{~N}$ load compared to other lubricants. At a higher load of $981 \mathrm{~N}$, all wear scars were still formed as a round shape but the edges were found ragged and serrated. The larger dark area was spotted as highlighted in Figure 12e which indicated that the thin monolayer soap film had broken down and unable to protect the contact surface at a higher load. Dark light scratches were classified as abrasive wear while some fused metal at the edge of the wear scar was considered as adhesive wear (Fazal et al., 2013).

At a load of $1179 \mathrm{~N}$, it was the point that the steel ball was found welded to each other, meaning that the lubricant was totally not functioning, leading to severe damage on the contact surface. It can be seen clearly that almost all metal surfaces were heaped
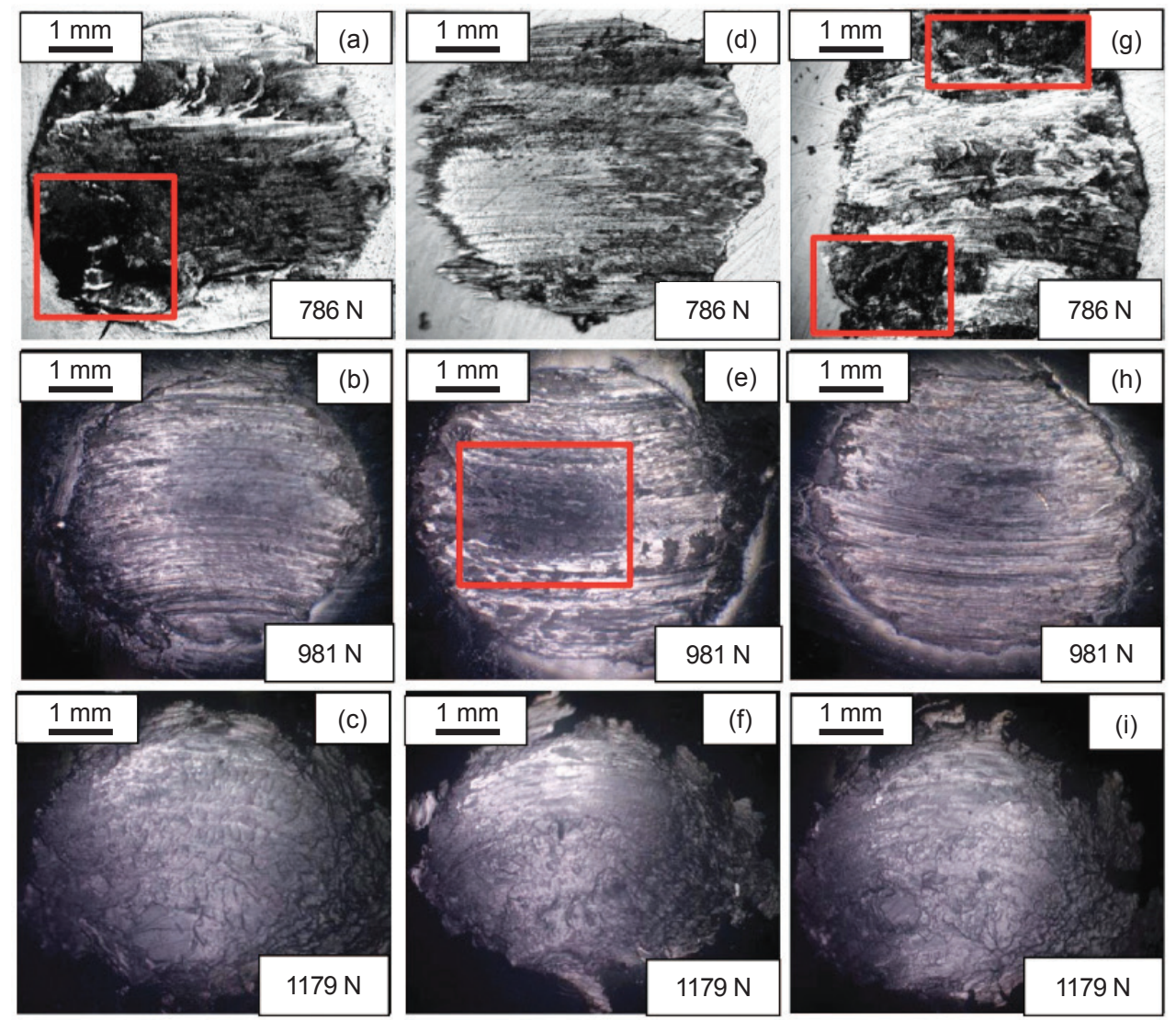

Note: RBDPO - refined, bleached and deodourised palm oil; SPL - double fractionated palm olein; PMO - palm mid olein.

Figure 12. Physical wear under extreme pressure condition (a-c) RBDPO, (d-f) SPL, and ( $g$-i) PMO. 
and fused together by the welding effect. Some of it had slipped away from its original position and removed out of the contact circle. The molecular interaction either by saturated and unsaturated fatty acid with the metal surface was unable to retain the formation of thin layer soap film (Kalam et al., 2012). It was also observed that the fatty acid content does not give a significant impact on EP condition. It can be stated that palm oil-based lubricants could only withstand a maximum load of $981 \mathrm{~N}$. Additional relevant additives might help in improving the capability of palm oil-based lubricants.

\section{CONCLUSION}

The fatty acid composition of palm oil-based lubricants was examined and evaluated. The tribological performances of each tested lubricant were also investigated and discussed thoroughly. It can be concluded that in various temperatures condition, PMO showed $8.9 \%$ and $4.9 \%$ lower coefficient of friction compared to SPL and RBDPO. On average, PMO also has 3.4\% and 3.8\% lower WSD compared to SPL and RBDPO. Meanwhile in various speeds analysis, PMO demonstrated 7.9\% and $13.4 \%$ lower coefficient of friction than SPL and RBDPO. Furthermore, PMO showed 11.8\% and $5.1 \%$ lower WSD compared to SPL and RBDPO respectively. SPL which has high saturated fatty acid content managed to reduce the coefficient of friction at various temperatures and rotational speeds. However, it was not giving any significant impact at a load of more than $981 \mathrm{~N}$ in EP conditions.

Stronger molecular interaction between saturated fatty acid molecules and the metal surface provided optimum protection against asperities contact, thus, promoted smoother Ra. In physical wear analysis, SPL which has a high unsaturated fatty acid content had experienced higher oxidation effects and hence resulted in severe damage on the contact surface at high temperatures and rotational speeds. However, the fatty acid content does not show any significant impact to the wear appearances at EP load of $981 \mathrm{~N}$ and $1179 \mathrm{~N}$. All palm oil-based lubricants were considered to meet the failure point at $1179 \mathrm{~N}$.

\section{ACKNOWLEDGEMENT}

The authors would like to express their thanks to the Ministry of Higher Education of Malaysia for the FRGS Grant (FRGS/1/2018/TK03/ UTM/02/14), Universiti Teknologi Malaysia (UTM) for the Research University Grant (21H50), TDR Grant (05G23) and FRGS Grant (5F074, 5F173).

\section{REFERENCES}

Aluyor, E O and Ori-Jesu, M (2008). The use of antioxidants in vegetable oils - A review. African J. Biotechnology, 7(25): 4836-4842.

Amiril, S A S; Rahim, E A; Embong, Z and Syahrullail, S (2018). Tribological investigations on the application of oil-miscible ionic liquids additives in modified Jatropha-based metalworking fluid. Tribology International, 120: 520-534.

ASTM International (2019). ASTM D2783-19, Standard test method for measurement of extreme pressure properties of lubricating fluids (four-ball method). West Conshohocken, PA.

Button, A (2017). US EIA raises forecast to world oil demand in 2016 and 2017. World liquid fuels production and consumption balance. https:// www.nasdaq.com/article / us-eia-raises-forecastto-world-oil-demand-in-2016-and-2017-cm619107, accessed on 31 January 2019.

Crespo, A; Morgado, N; Mazuyer, D and CayerBarrioz, J (2018). Effect of unsaturation on the adsorption and the mechanical behaviour of fatty acid layers. Langmuir, 34(15): 4560-4567.

Doig, M; Warrens, C P and Camp, P J (2014). Structure and friction of stearic acid and oleic acid films adsorbed on iron oxide surfaces in squalane. Langmuir, 30(1): 186-195.

Fazal, M A; Haseeb, A S M A and Masjuki, H $H$ (2013). Investigation of friction and wear characteristics of palm biodiesel. Energy Conversion and Management, 67: 251-256.

Farhanah, A N and Syahrullail, S (2016). Evaluation of lubrication performance of RBD palm stearin and its formulation under different applied loads. J. Tribologi, 10: 1-15.

Habibullah, M; Masjuki, H H; Kalam, M A; Ashraful, A M; Habib, M A and Mobarak, H M (2014). Effect of bio-lubricant on tribological characteristics of steel. Procedia Engineering, 90: 740-745.

Haseeb, A S M A; Sia, S Y; Fazal, M A and Masjuki, $\mathrm{H} \mathrm{H}$ (2010). Effect of temperature on tribological properties of palm biodiesel. Energy, 35(3): 14601464.

Hassan, M; Ani, F N and Syahrullail, S (2016). Tribological performance of refined, bleached and deodourised palm olein blends bio-lubricants. J. Oil Palm Res. Vol. 28(4): 510-519. 
Jabal, M H; Ani, F N and Syahrullail, S (2014). The tribological characteristic of the blends of RBD palm olein with mineral oil using four-ball tribotester. Jurnal Teknologi, 69(6): 11-14.

Kalam, M A; Masjuki, H H; Shahabuddin, $\mathrm{M}$ and Mofijur, M (2012). Tribological characteristics of amine phosphate and octylated/butylated diphenylamine additives infused bio-lubricant. Energy Education Science and Technology Part A: Energy Science and Research, 30(1): 123-136.

Kondo, H (1997). Effect of double bonds on friction in the boundary lubrication of magnetic thin film media. Wear, 202(2): 149-153.

Lundgren, S M; Ruths, M; Danerlöv, K and Persson, K (2008). Effects of unsaturation on film structure and friction of fatty acids in a model base oil. J. Colloid and Interface Science, 326(2): 530-536.

Lundgren, S M; Persson, K; Clarke, J; Nordstierna, L and Claesson, P M (2011). The influence of water on the adsorption and the tribological properties of unsaturated fatty acids in alkane solution. Proc. of the Institution of Mechanical Engineers, Part J: J. Engineering Tribology, 225(10): 1048-1055.

Mannekote, J K and Kailas, S V (2012). The effect of oxidation on the tribological performance of few vegetable oils. J. Materials Research and Technology, 1(2): 91-95.

Mobarak, H M; Masjuki, H H; Mohamad, E N; Rahman, S A; Al Mahmud, K A H; Habibullah, M and Salauddin, S (2014). Effect of DLC coating on tribological behaviour of cylinder liner-piston ring material combination when lubricated with Jatropha oil. Procedia Engineering, 90: 733-739.

Noorawzi, N and Samion, S (2016). Tribological effects of vegetable oil as alternative lubricant: A pin-on-disk tribometer and wear study. Tribology Transactions, 59(5): 831-837.

Quinchia, LA; Delgado, M A; Reddyhoff, T; Gallegos, C and Spikes, H A (2014). Tribological studies of potential vegetable oil-based lubricants containing environmentally friendly viscosity modifiers. Tribology International, 69: 110-117.
Razak, D M; Syahrullail, S; Sapawe, N; Azli, Y and Nuraliza, N (2015). A new approach using palm olein, palm kernel oil, and palm fatty acid distillate as alternative biolubricants: Improving tribology in metal-on-metal contact. Tribology Transactions, 58(3): 511-517.

Sahoo, R R and Biswas, S K (2009). Frictional response of fatty acids on steel. J. Colloid and Interface Science, 333(2): 707-718.

Sapawe, N; Samion, S; Zulhanafi, P; Nor Azwadi, C S and Hanafi, M F (2016). Effect of addition of tertiary-butyl hydroquinone into palm oil to reduce wear and friction using four-ball tribotester. Tribology Transactions, 59(5): 883-888.

Sharma, B K; Adhvaryu, A and Erhan, S Z (2009). Friction and wear behaviour of thioether hydroxy vegetable oil. Tribology International, 42(2): 353-358.

Syahrullail, S; Kamitani, S and Shakirin, A J P E (2013a). Performance of vegetable oil as lubricant in extreme pressure condition. Procedia Engineering, 68(0): 172-177.

Syahrullail, S; Wira, J. Y; Wan Nik, W B and Fawwaz, W N (2013b). Friction characteristics of RBD palm olein using four-ball tribotester. Applied Mechanics and Materials (Vol. 315). Trans Tech Publications Ltd. p. 936-940.

Syahrullail, S; Hariz, M A M; Hamid, M A and Bakar, A A (2013c). Friction characteristic of mineral oil containing palm fatty acid distillate using four ball tribo-tester. Procedia Engineering, 68: 166-171.

Totten, G E; Westbrook, S R and Shah, R J (2003). Fuels and Lubricants Handbook: Technology. Properties, Performance and Testing. ASTM International. 1086 pp.

Zulhanafi, P and Syahrullail, S (2019). The tribological performances of super olein as fluid lubricant using four-ball tribotester. Tribology International, 130: 85-93.

Zulkifli, N W M; Kalam, M A; Masjuki, H H; Shahabuddin, M and Yunus, R (2013). Wear prevention characteristics of a palm oil-based TMP (trimethylolpropane) ester as an engine lubricant. Energy, 54: 167-173. 